\title{
How helpful are mnemonics in the development of a research question?
}

\author{
Helen Sisson, Faculty of Health and Social Work. University of Hull
}

\section{Introduction}

A focussed question is the first challenge presented to researchers, and the literature is unanimous in its support of this view, citing issues of clarity and conciseness as key considerations (Parahoo, 2014; Tully, 2014). Much published work has focussed on supporting the development of a research question which is relative to practice and can be applied and translated into research (Connelly, 2015; O'Brien \& DeSisto, 2013). Other authors have acknowledged the importance of the research question to facilitate an effective literature search (Meadows, 2003; Macfarlane et al., 2015). Supporting the development of the research question, has seen the emergence of a variety tools or frameworks; whilst the published literature recognises that these frameworks are there to aid researchers, this paper aims to provide a synopsis of them and consider how they may both assist and impede the development of a research question.

\section{Background}

The identification of a research question is a stage of the research process which is a key determinant in the production of useable results (Hastings \& Fisher, 2014) and several considerations are recognised as being crucial to this stage. Meadows (2003) emphasises the role of the literature review in identifying existing research, whilst Burns and Grove (2011) highlight the issues of relevance, feasibility, focus and ethics. From another perspective, Lipowski (2008) iterates the value of making the research question interesting, and suggests that this may be achieved by taking an individual standpoint thus making the question more 
relevant and meaningful to practice. An additional matter when undertaking empirical research concerns the selected methodology, with quantitative designs focussing on predetermined measures to answer the question, and qualitative designs being concerned with describing phenomena to gain greater understanding (Gray et al., 2017). Such diverse approaches to research suggest that an equally diverse approach to developing the research question may be required. Johnson and Hengstberger-Sims (2011) outline some characteristics of a 'good' quantitative research question and state that it should comprise six components: the participants, clinical context, phenomenon of interest, intervention, comparison group and outcomes. With a focus on qualitative research, Mantzoukas (2008) writes that the question should reveal the area of interest in a succinct, focussed and practicable manner; moreover, it may not conform to the traditional format of a question and it may be presented in the form of a declarative statement. The development of a research question is often a requirement in academic study and personal experience of supervising students, suggests that this is an activity which presents a significant challenge. This may be due to the previously mentioned considerations being difficult for some students to grasp; they may be novices at searching the literature, unfamiliar with research methods, or even relatively inexperienced practitioners and are therefore, less well equipped in terms of both skills and knowledge. Flemming (1998) discusses the need for the research question to be answerable and Connelly (2015) and Tully (2014) both acknowledge that proposing a question which is either too narrow or too broad is a common occurrence among novice researchers. However, such challenges are not confined to the student population or those starting out in research; experienced practitioners and researchers too may have difficulty in framing a 'good' research question (Johnson and Hengstberger-Sims, 2011) and to address this problem 
some frameworks have been developed. The remainder of this paper identifies four of these frameworks and considers their ability to facilitate the development of a research question.

\section{Identified frameworks}

The frameworks which have been developed to support the identification of research questions are largely represented as mnemonics, and their application is demonstrated with the use of some hypothetical enquiries (Table 1).

Table 1. Identified frameworks

\begin{tabular}{|l|l|l|}
\hline Mnemonic & Origins & $\begin{array}{l}\text { Sample (hypothetical) } \\
\text { question/statement }\end{array}$ \\
\hline $\begin{array}{l}\text { PICO (T) - patient/problem (P), } \\
\text { intervention (I), comparison (C), } \\
\text { outcome (O), (time)(T) }\end{array}$ & $\begin{array}{l}\text { Oxman et } \\
\text { al. (1993) } \\
\text { Richardson } \\
\text { et al. } \\
(1995)\end{array}$ & $\begin{array}{l}\text { A study comparing the healing rates } \\
\text { (O) of two types of dressing (I) (C) } \\
\text { used in diabetic patients with foot } \\
\text { ulcers (P) over a six week period (T) }\end{array}$ \\
\hline $\begin{array}{l}\text { PI/EO - population (P), } \\
\text { intervention/exposure (I /E), } \\
\text { outcome (O) }\end{array}$ & $\begin{array}{l}\text { Khan et al. } \\
(2003),\end{array}$ & $\begin{array}{l}\text { How does compulsory academic } \\
\text { supervision (I/E) impact on grades (O) } \\
\text { in first year nursing students (P)? }\end{array}$ \\
\hline $\begin{array}{l}\text { SPIDER - sample (S), phenomena of } \\
\text { interest (PI), design (D), evaluation } \\
\text { (E), research type (R) }\end{array}$ & $\begin{array}{l}\text { Cooke et } \\
\text { al. (2012) }\end{array}$ & $\begin{array}{l}\text { A qualitative study (R) using focus } \\
\text { groups (D) exploring the experiences } \\
\text { (E) of adolescent fathers (S) in the } \\
\text { delivery room (PI) }\end{array}$ \\
\hline $\begin{array}{l}\text { PICOT-D - population (P), } \\
\text { intervention (I), comparison (C), } \\
\text { outcome (O), time (T) - digital (D) }\end{array}$ & $\begin{array}{l}\text { Elias et al. } \\
(2015)\end{array}$ & $\begin{array}{l}\text { In children with gastro-oesophageal } \\
\text { reflux (P), how does current } \\
\text { treatment (I) compare with a new } \\
\text { treatment (C), when looking at pH } \\
\text { levels (O) over a 24 hour period (T) } \\
\text { using data recorded on the pH sensor } \\
\text { (D)? }\end{array}$ \\
\hline
\end{tabular}

$\mathrm{PICO}(\mathrm{T})$ is the most frequently cited framework in the literature and is also the earliest framework to have been developed. Its origins lie in epidemiology, focussing largely on a patient-exposure approach to the development of research questions, for both framing a problem which has emerged from practice, and for identifying the relevant evidence (Oxman 
et al., 1993). This was further modelled by Richardson et al. (1995) and the familiar PICO mnemonic appeared. Expanding on the relationship between the patient and exposure, Richardson et al. (1995) identified intervention (I), comparison (C), and outcome (O). The patient/problem $(\mathrm{P})$ is more latterly referred to as 'population' and the fifth dimension of time (T) has been included (McKeon \& McKeon, 2015; Echevarria \& Walker, 2014). Much of the published literature offers guidance on how $\mathrm{PICO}(\mathrm{T})$ may be practically applied in the establishment of a research question and the context of its use varies between identifying the relevant literature for a systematic review (Schardt et al., 2007) and framing questions for empirical study (Riva et al., 2012). A further expansion of the PICO(T) framework is proposed by Elias et al. (2015), in the form of PICOT-D. Given the increased availability of existing data to inform an evidence based approach to practice, Elias et al. (2015) have added digital (D) to PICOT.

With its concepts of intervention and comparison the PICO(T) framework clearly suggests that its application is more suited to quantitative enquires, an observation which has been identified in the literature (Miller \& Forrest, 2001; Moule \& Goodman,2009). Cooke et al. (2012) acknowledged the increasing use of inductive approaches arguing the need for a framework which was more suited to a qualitative paradigm and subsequently developed SPIDER; sample (S), phenomenon of interest $(P, I)$, design (D), evaluation (E) and research type $(\mathrm{R})$. They reason that the shift from population $(\mathrm{P})$ to sample $(\mathrm{S})$ and intervention $(\mathrm{I})$ to phenomenon of interest $(P, I)$, better reflect the nature and purpose of qualitative enquiries (Cooke et al., 2012). Equally and for similar reasons, comparison (C) is replaced with design (D) and evaluation (E) replaces outcome (O). Cooke et al. (2012) suggest that the addition of research type (R) may make SPIDER appropriate for mixed-methods and quantitative search strategies, nonetheless, its use appears to be mainly confined to qualitative paradigms 
(Aveyard, 2014). However, Fineout-Overholt and Stillwell (2011) illustrate how PICOT can be adapted to support qualitative enquiries and suggest that in these situations, the $\mathrm{C}$ and $\mathrm{T}$ may not always be appropriate. Khan et al. (2003) also acknowledge qualitative approaches and have suggested patient $(P)$, exposure $(E)$, outcome $(O)$ as a framework which may be used in the development of questions. However, more recently, Khan et al. (2011) have moved away from the use of mnemonics in formulating questions for reviews, instead the discourse focusses on four components; the population, the intervention (or exposure), the outcome and the study design. Whilst acknowledging the importance of structure, Khan et al. (2011) advocate a flexible approach to the development of questions.

\section{Practical application}

Developing a research question can be an intricate matter and using these frameworks can help to identify the scope and articulation of a specific research question; although almost exclusively limited to PICO, the literature is littered with examples of how they may be applied (Aslam \& Emmanuel, 2010; Miller \& Forrest, 2001). Even so, rather than help in the establishment of a research question, experience suggests that the use of mnemonics can actually result in confusion. Less experienced students have presented work where attempts have been made to inappropriately align their research questions with the selected mnemonics, thus in the case of PICO for example, have misinterpreted its elements as vital components of all research questions, rather than serving as an intention to guide question development. Such issues are not confined to inexperienced students however; recent personal experience of identifying a question for a systematic review of the literature resulted in some frustration as even a flexible approach to the use of the mnemonics was ambiguous. PICO is the longest established mnemonic with a valued history in nursing (Elias et al., 2015) yet its application to qualitative paradigms is less well recognised (Aveyard, 2014; Cooke et 
al., 2012). Additionally, PICO may not always be relevant in all nursing settings; Carman et al. (2008) draw upon the example of experimental approaches (approaches for which PICO is ideal) in the emergency department where randomised controlled trials are seldom possible. These problems have been acknowledged by Echevarria et al. (2014) who highlight the usefulness of the templates developed by Fineout-Overholt and Stillwell (2011). The templates are structured around PICOT but consider the type of question and PICOT is adapted accordingly. The issue here is in understanding the purpose and limitations of such frameworks in establishing the research question and using their components as a guide rather than an essential requirement.

In considering the value of these frameworks, it is useful to revisit the reasons for their inception. Oxman et al. (1993) asserted the ability to efficiently identify research which was relevant to practice as a driver in the development of frameworks. Similarly, Doody and Bailey (2016) write that frameworks have been developed in response to the need to have a focussed and clearly articulated research question and Cooke et al. (2012) cite that such frameworks are helpful to facilitate the identification of relevant search terms. Despite their varying terminology, all of the mnemonics considered in this paper appear to subscribe to these motives. Furthermore, if the characteristics of a 'good' research question cited by Johnson and Hengstberger-Sims (2011) are reconsidered (participants, clinical context, phenomenon of interest, intervention, comparison group and outcomes), it becomes clear that the frameworks cited in Table 1 are fitting. Khan et al. (2011) have moved away from using mnemonics as an aid to developing research questions. This may be due to the perceived rigidity of such frameworks and Khan et al. (2011:12) advise that even their own suggested structure should not become a 'straight jacket', but that it should be adapted to meet the needs of the topic and approach. Misuse of the mnemonics by less experienced 
researchers may also be a valid reason to discourage their use, or if they are to be applied then advice regarding their use should include some cautionary notes. As tempting as it is to summarise the existing frameworks into a new mnemonic, there are enough in the literature for researchers to refer to. What is important is that Johnson and Hengstberger-Sims' (2011) characteristics of a 'good' research question are considered, whether the question is being developed for evidence retrieval or empirical study.

\section{Conclusion}

The literature consistently reminds researchers that the establishment of a clear and focussed research question is crucial to the success or failure of any subsequent work, and assistance in the form of frameworks are abundant. This paper has identified some frameworks which have been developed to help researchers and although they vary significantly depending on the context of their use, they share fundamental elements which are consistent with Johnson and Hengstberger-Sims' (2011) characteristics of a 'good' research question. It is vital that if such frameworks are used to aid the development of a research question, their limitations are acknowledged and that they are used to provide guidance rather than in an exacting manner, and this may be especially pertinent to novice researchers.

\section{References}

Aslam S, Emmanueal P (2010) Formulating a researchable question: A critical step for facilitating good clinical research. Indian Journal of Sexually Transmitted Disease. 31, 1, 47-50. Aveyard H (2014) Doing a Literature Review in Health and Social Care, a practical guide. Third edition. Open University Press, Maidenhead.

Burns N, Grove SK (2011) Understanding nursing research: building an evidence based practice. Fifth edition. Elsevier Saunders, London. 
Carman MJ, Wolf LA, Henderson D, Kamienski M, Koziol-McLain J, Moon MD (2013) Developing your clinical question: The key to successful research. Journal of Emergency Nursing. 39, 3, 299-301.

Connelly LM (2015) Research Questions and Hypotheses. MEDSURG Nursing. 24, 6, 435-436.

Cooke A, Smith D, Booth A (2012) Beyond PICO: The SPIDER Tool for Qualitative Evidence Synthesis. Qualitative Health Research. 22, 10, 1435-1443.

Doody O, Bailey ME (2016) Setting a research question, aim and objective. Nurse Researcher. 23, 4, 19-23.

Echevarria I, Walker S (2014) To make your case, start with a PICOT question. Nursing. 6, 26, 18-19.

Elias BL, Polancich S, Jones C, Convoy S (2015) Evolving the PICOT Method for the Digital Age: The PICOT-D. Journal of Nursing Education. 54, 10, 954-599.

Fineout-Overholt E, Stillwell SB (2011) Asking Compelling, Clinical Questions. In Melnyk BM, Fineout-Overholt E (Eds) Evidence-Based Practice in Nursing and Healthcare. Second edition. Lippincott Williams \& Wilkins, Philadelphia, 25-39.

Flemming K (1998) Asking answerable questions. Evidence-Based Nursing. 1, 2, 36-37.

Gray JR, Grove SK, Sutherland S (2017) The practice of Nursing Research. Eighth Edition. Elsevier Inc, Missouri.

Hastings C, Fisher C (2014) Searching for proof: creating and using an actionable PICO question. Nursing Management. 45, 8, 9-12.

Johnson M, Hengstberger-Sims C (2011) Introducing the research process. Jirowong S, Johnson M, Welch A (Eds) Research Methods in Nursing and Midwifery: Pathways to Evidence-Based Practice. Oxford University Press, Melbourne, 23-51.

Khan KS, Kunz R, Kleijnen J, Antes G (2003) Systematic Reviews to Support Evidence-Based Medicine: How to Review and Apply Findings of Healthcare Research. Royal Society of Medicine Press, London.

Khan KS, Kunz R, Kleijnen J, Antes G (2011) Systematic Reviews to Support Evidence-Based Medicine: How to Review and Apply Findings of Healthcare Research. Second edition. Hodder Arnold, London.

Lipowski EE (2008) Developing great research questions. American Journal of Health-System Pharmacy. 65, 17, 1667-1670.

Macfalane MD, Kisely S, Loi S, Looi JC, Merry S, Parker S, Power B, Siskind D, Smith G, Macfarlane $S$ (2015) Getting started in research: research questions, supervisors and literature reviews. Australasian Psychiatry. 23, 1, 8-11.

Mantzoukas S (2008) Facilitating research students in formulating qualitative research questions. Nurse Education Today. 28, 371-377.

McKeon JMM, McKeon PO (2015) PICO: A Hot Topic in Evidence-Based Practice. International Journal of Athletic Therapy Training. 20, 1, 1-3. 
Meadows KA (2003) So you want to do research? 2: developing the research question. British Journal of Community Nursing. 8, 9, 397-403.

Miller SA, Forrest JL (2001) Enhancing your practice decision making: PICO, good qustions. Journal of Evidence Based Dental Practice. 1, 2, 136-141.

Moule P, Goodman M (2009) Nursing Research, An Introduction. Sage Publications Ltd, London.

O'Brien MJ, DeSisto MC (2013) Every Study Begins With a Query. National Association of School Nurses, School Nurse. 28, 2, 83-85.

Oxman AD, Sackett DL, Guyatt GH (1993) Users' Guides to the Medical Literature. 1. How to get started. JAMA, 270, 17, 2093-2095.

Parahoo K (2014) Nursing research, Principle, Process and Issues. Third edition. Palgrave Macmillan, Basingstoke.

Richardson WS, Wilson MC, Nishikawa J, Hayward RS (1995) The well-built clinical question: A key to evidence-based decisions. American College of Physicians Journal Club, 123, 3, A12A13.

Riva JJ, Malik KMP, Burnie SJ, Endicott AR, Busse JW (2012) What is your research question? An introduction to the PICOT format for clinicians. Journal of Canadian Chiropractic Association. 56, 3, 167-171.

Schartd C, Adams MB, Owens T, Keitz S, Fontelo P (2007) Utilization of the PICO framework to improve searching PubMed for clinical questions. BMC Medical Informatics and Decision Making. 7, 16, 1-6.

Tully P (2014) Research: Articulating Questions, Generating Hypotheses, and Choosing Study Designs. Canadian Journal of Hospital Pharmacy. 67, 1, 31-34. 